\title{
Current treatment options for the management of patent ductus arteriosus
}

This article was published in the following Dove Press journal:

Pediatric Health, Medicine and Therapeutics

25 March 2013

Number of times this article has been viewed

Koh Takeuchi'

Atsushi Hirota ${ }^{2}$

Sachito Minegishi'

Jotaro Kobayashi'

Keiji Tsuchiya ${ }^{3}$

'Division of Cardiovascular Surgery,

2Department of Neonatology,

${ }^{3}$ Department of Pediatrics, Japanese

Red Cross Medical Center, Shibuya,

Tokyo, Japan
Correspondence: Koh Takeuchi

Division of Cardiovascular Surgery, Japanese Red Cross Medical Center,

4-I-22, Hiroo, Shibuya, Tokyo,

I50-8935, Japan

$\mathrm{Tel}+8 \mid 33400$ I3 I I

Fax $+8 \mid 334091604$

Email koutakeuchi-circ@umin.ac.jp
Abstract: Pharmacological and/or surgical closure of a hemodynamically significant patent ductus arteriosus (PDA) in the very premature infant has been the standard of care over the past few decades. However, the rationale for closure of PDA has recently been challenged. In this article, three ways of approaching the closure of PDA including pharmacological treatment, catheter intervention, and surgical intervention, are reviewed in detail. In addition, the different treatment strategies applied in clinical care are evaluated with a focus on the discussion of the available evidence of PDA treatment in the literature.

Keywords: patent ductus arteriosus, premature infant, treatment option

Over the last three decades, knowledge about fundamental and clinical aspects of the ductus arteriosus has substantially improved, leading to considerable progress in the management of various cardiac diseases including patent ductus arteriosus (PDA). PDA is a frequently occurring pathological congenital cardiac condition in low birth weight premature neonates. The consequences of a significant left-to-right shunting through the PDA may present hemodynamic and respiratory importance. ${ }^{1}$ Spontaneous closure of the PDA in normal birth weight neonates occurs in 3 days, but it may persist longer in the premature baby. ${ }^{2}$ The identification of the mechanisms regulating ductal patency led to the design of pharmacological drugs to achieve medical closure of PDA in the premature infant, or inversely to maintain patency of PDA in neonates with ductus dependent congenital heart diseases. Concurrently, widespread availability of echocardiography has improved the detection of congenital PDA, resulting in earlier treatment. Closure of PDA, either by surgery or transcatheter techniques, can now be achieved safely in relatively large patients, resulting in a decrease in the incidence of severe complications of PDA. In this article, both updated and alternative treatments will be discussed. PDA often complicates the clinical course of neonates born prematurely and increases their shortand long-term morbidity. PDA is present in up to $70 \%$ of preterm infants born before 28 weeks gestation. ${ }^{1}$ Treatment of PDA remains an ongoing debate among neonatologists for various reasons, including the timing, the criteria, and the methods for its closure. We will discuss these in the following sections. We will also show our recent surgical results for PDA clipping of very low birth weight babies in our institution.

\section{Pharmacological treatment of PDA in preterm infants}

Muscular constriction produces a region of ischemic hypoxia in the middle of the ductus muscle media that initiates the process of permanent closure of PDA. This is a 
theoretical background to attempt pharmacological closure of PDA by inducing muscle constriction of PDA. A non steroidal anti-inflammatory drug such as indomethacin ${ }^{3}$ has been traditionally used as the treatment of choice for PDA. Its use, however, has waned due to the recognition of renal, cerebral, and gastrointestinal complications associated with the administration of this drug. Other non steroidal anti-inflammatory drugs have been investigated, but either the profile of adverse effects was unfavorable, as in the case of mefenamic acid, or their efficacy was less than that of indomethacin for PDA closure. More recently, ibuprofen has emerged in clinical practice as it has been reported to have lower nephrotoxicity ${ }^{4-6}$ if used enterally. However, since renal perfusion, Glomerular Filtration Rate (GFR), and dieresis in early neonatal life strongly depend on the vasodilator effects of prostaglandins on the afferent glomerular arterioles, ibuprofen, like other cyclooxygenase (COX) inhibitors may not be exempt from causing some undesirable renal effects. A previous paper ${ }^{7}$ reviewed ten trials for meta-analysis of indomethacin versus ibuprofen for PDA in the preterm infant. The trials compared intravenous indomethacin versus intravenous ibuprofen: nine trials compared intravenous indomethacin versus placebo and one trial compared intravenous ibuprofen versus placebo. The results suggested that both intravenous indomethacin (pooled relative risk [RR] 2.39, 95\% CI 2.05-2.78) and intravenous ibuprofen (RR 2.40, 95\% CI 2.03-2.84) closed a PDA more effectively than the placebo. Intravenous ibuprofen was associated with an approximately $30 \%$ greater risk of chronic lung disease than intravenous indomethacin (RR $1.28,95 \%$ CI 1.03-1.6). Other papers ${ }^{8,9}$ suggested no significantly greater benefits from ibuprofen administration. When administered for prophylaxis, ibuprofen has no effect on the prevention of intraventricular hemorrhage (IVH) unlike indomethacin. ${ }^{3}$ A trial of continuous infusion versus intermittent bolus doses of indomethacin for PDA closure ${ }^{10}$ suggested no statistical difference between the bolus and continuous groups for the secondary outcomes of reopening of PDA, neonatal mortality, IVH, and necrotizing enterocolitis.

\section{Transcatheter PDA occlusion}

Relatively large patients with PDA can be treated by catheter intervention, which has become a more common treatment in such patients than surgical intervention. Occlusion of PDA was first described in 1971 with an Ivalon plug. ${ }^{11}$ This was followed by Rashkinds et al who used a hooked single disk device in 1979 and a double disk device in $1987 .{ }^{12}$ Cambier et $\mathrm{al}^{13}$ reported a small series using Gianturco coils to occlude small PDAs. The major advantage of this technique was the use of a small ( 5 Fr.) delivery system. Since then, transcatheter occlusion of PDAs with a variety of devices and innovative techniques has been reported. ${ }^{14-22}$ Both safety and efficacy have been established in many series, and this treatment modality has become a standard of care at many centers except in very low birth weight patients or those with unsuitable anatomy, such as the type B (also known as the AP window type) PDA..$^{23}$ The most common devices currently used are various kinds of coils and the AMPLAZER ${ }^{\mathrm{TM}}$ ductal occluder device. Many prograde and antegrade techniques have been developed to deliver coils to maximize occlusion and to minimize the risk of coil embolization. $^{24-26}$

Indications for PDA occlusion are elimination of pulmonary overcirculation and subsequent development of obstructive pulmonary vascular disease, as well as prevention of endocarditis and/or endarteritis. There is controversy related to occlusion of the so-called silent ductus. There is little data on the benefits of occluding the silent ductus because of its small size, and presumably, the lack of significant flow turbulence and endothelial damage. In those patients with a large PDA and bidirectional flow due to pulmonary vascular disease, occlusion may be indicated only if the pulmonary lung bed shows some reactivity to pulmonary vasodilator therapies. ${ }^{27,28}$

\section{Surgical clipping/ligation of PDA}

The consequences of a significant left-to-right shunt through the PDA may present hemodynamic and respiratory instability. ${ }^{29}$ Whilst awaiting spontaneous closure of PDA or pharmacological intervention, prolonged endotracheal intubation, mechanical respiratory support, and related problems may complicate the condition. Surgical closure is an option for cases where a medical intervention may not be sufficient. PDA ligation produces permanent ductus closure, improves pulmonary mechanics, and decreases the need for prolonged ventilator support. Recent studies, however, suggest that in addition to the known surgical complications that may accompany the procedure such as pneumothorax, recurrent nerve palsy, ${ }^{30}$ and $\mathrm{IVH},{ }^{31}$ the ligation itself may directly contribute to some of the neonatal morbidities. Previous studies have shown that early surgical ligation decreases alveolar water clearance, impedes lung growth, and increases the expression of genes involved with pulmonary inflammation. ${ }^{32}$ Several studies have demonstrated that infants treated with surgical ligation 
of PDA had a significant increase in adverse outcomes. ${ }^{33-35}$ The timing of surgery is still a controversial issue. One recent report suggested that the prolonged patency of the PDA in preterm infants is related to increased morbidity, including bronchopulmonary dysplasia and acute renal failure. ${ }^{36}$ They suggested that surgical ligation of PDA is a safe and effective treatment and should be done soon after two complete cycles of ibuprofen, especially in patients at a younger gestational age $(<25$ weeks $)$, lower body weight at birth, and a higher incidence of symptomatic hypotension, in order to improve the clinical outcome. ${ }^{36}$ Another retrospective study looking at the timing of the surgical intervention suggests that early ligation $(<14$ days of life) of medically refractory PDA in very low birth weight premature infants improves enteral feeding tolerance and reduces total parenteral nutrition and ventilator use..$^{30}$ A recent observational study indicated an increased risk for one or more of the following outcomes associated with PDA ligation: chronic lung disease, retinopathy of prematurity, and neurosensory impairment. ${ }^{37}$ Another paper suggested that ductal ligation poses a risk for a further decrease in already compromised cerebral oxygenation in preterm infants. ${ }^{38}$ However the ductal clipping has been reported to have no negative effect on cerebral oxygenation. ${ }^{39}$ It is possible that the duration of the "waiting time" and transport to another facility with surgical capacity in order to have the PDA ligated or clipped could adversely affect outcomes, as could the perioperative care. Jhaveri et $\mathrm{al}^{40}$ compared two different treatment approaches for infants ( $\leq 27$ weeks gestation) with PDAs that failed to close after indomethacin treatment: (1) the "early ligation" approach that limited the exposure to the PDA shunt by ligating the PDA soon after indomethacin failure; and (2) a "selective ligation" approach that "tolerated" the presence of the PDA shunt and used surgical ligation only if specific criteria were met. They found that the "selective ligation" approach produced a significant decrease in the rate of ductus ligation and a significant decrease in the rates of necrotizing enterocolitis and of neurodevelopmental abnormality at $18-36$ months. ${ }^{40,41}$ The delay in ligation appears to be beneficial because accumulating evidence suggests that several of the morbidities associated with ligation including post ligation hypotension, ${ }^{42}$ vocal cord paralysis, ${ }^{43}$ bronchopulmonary dysplasia, ${ }^{44}$ and abnormal neurodevelopmental outcomes ${ }^{41}$ are significantly reduced when ligation is delayed. Further investigation is warranted to determine which infants are most likely to benefit from surgical closure and which infants might be left untreated when pharmacological approaches are no longer available.

\section{Outcome of surgical clipping of PDA in preterm infants in our institution \\ Methods and materials}

Our hospital is a tertiary medical care center and perinatal care center for high risk pregnancies. Premature patients with isolated PDA and very lower body weight (body weight $<1500$ grams) who underwent ductal clipping between January 2006 and December 2011 are included in this study. We have used a clipping technique rather than a ligation technique as the surgical incision is only $2 \mathrm{~cm}$ in length. Patients with genetic disorders, and/or CHARGE syndrome, or other cardiac diseases were excluded from this study. Of the 102 patients involved in this study, 86 patients were extremely low birth weight babies (birth weight $<1000$ grams). These patients were subdivided into two groups: (1) early clipping (EC) of medically refractory PDA ( $\leq 14$ days), and (2) late ( $>14$ days) clipping (LC) of medically refractory PDA after failure of medical treatment or having contraindications to medical treatment. There were 33 patients in the EC group and 69 patients in the LC group. Basic clinical features, major morbidity of prematurity, and mortality were compared.

\section{Results}

Clinical features and major outcomes between the EC and LC groups were similar (Table 1). When compared with the LC group, the EC group had earlier onset of symptomatic PDA (mean $\pm \mathrm{SD} ; 7.8 \pm 3.0$ days versus $28.5 \pm 8.7$ days, $P<0.05$ )

Table I Patient background

\begin{tabular}{|c|c|c|c|}
\hline & $\begin{array}{l}\text { Early clipping } \\
\text { group }(n=33)\end{array}$ & $\begin{array}{l}\text { Late clipping } \\
\text { group }(n=69)\end{array}$ & $P$ value \\
\hline Birth in our hospital (I) & 10 & 21 & \\
\hline Birth at outside & 23 & 48 & \\
\hline \multicolumn{4}{|l|}{ hospital (O) } \\
\hline I/O ratio & 0.43 & 0.44 & NS \\
\hline Gestational age (weeks) & $26.5 \pm 3.4$ & $25.0 \pm 2.2$ & NS \\
\hline Birth weight (grams) & $693 \pm 232$ & $799 \pm 324$ & NS \\
\hline Day of life at surgery & $7.2 \pm 2.7$ & $36.5 \pm 46.0$ & \\
\hline $\begin{array}{l}\text { Body weight at surgery } \\
\text { (grams) }\end{array}$ & $685 \pm 256$ & $862 \pm 351$ & $P<0.01$ \\
\hline
\end{tabular}

Note: All values are expressed as mean \pm SD.

Abbreviations: I, births in our hospital; O, births at other hospitals; NS, not significant. 
Table 2 Complications related to transportation

\begin{tabular}{llll}
\hline & EC $(\mathbf{n}=\mathbf{2 3})$ & LC $(\mathbf{n}=\mathbf{4 8})$ & P value \\
\hline IVH & 3 & 0 & NS \\
Hypotension & $\mathrm{I}$ & 5 & NS \\
Hypoxia & $\mathrm{I}$ & 6 & NS \\
Hypothermia & $\mathrm{I}$ & 4 & NS \\
Unscheduled extubation & 0 & $\mathrm{I}$ & $\mathrm{NS}$ \\
\hline
\end{tabular}

Abbreviations: EC, early clipping group; LC, late clipping group; IVH; intraventricular hemorrhage; NS, not significant.

and lower body weight at surgery $(685 \pm 256$ grams versus $862 \pm 351$ grams, $P<0.01)$. Among the 71 patients transported to our facility, including 23 patients in the EC group and 48 patients in the LC group, there were several adverse effects (Table 2). These include three IVH in the EC group but none in the LC group, hypotension in six patients, hypoxia in seven patients, hypothermia in five patients, and accidental extubation in one patient. One death occurred during the surgery because of aortic dissection. Of the 102 patients, 70 patients were discharged from our hospital to their referring hospitals. Of the 32 patients who remained in our hospital, their postoperative complications include recurrent nerve palsy in four patients and ductal aneurysm in one patient. Four and three deaths occurred in the EC group and the LC group, respectively, during the postoperative course. All four patients in the EC group and two patients in the LC group died due to sepsis, and one patient in the LC group died due to duodenal perforation followed by peritonitis/sepsis (Table 3). Most complications occurred in patients born in our hospital. This may be related to the fact that our institution is one of three perinatal care centers for high risk pregnancy in metropolitan Tokyo. In fact, the average body weight at surgery was significantly less in babies born in our hospital than in those born at other hospitals (685 \pm 180 grams versus $828 \pm 226$ grams, $P<0.05)$. Although surgical ductal clipping can be done safely, transportation may be a risk for symptomatic premature infants, particularly in patients requiring early ductus clipping. Precaution for sepsis may also be warranted.

Table 3 Postoperative complications and outcome

\begin{tabular}{llll}
\hline & EC $(\mathbf{n}=\mathbf{I 0})$ & LC $(\mathbf{n}=\mathbf{2 I})$ & $\mathbf{P}$ value \\
\hline $\begin{array}{l}\text { Left recurrent nerve palsy } \\
\text { Aneurysmal formation }\end{array}$ & $\mathrm{I}$ & $3(3)$ & NS \\
of PA & & $\mathrm{I}(1)$ & NS \\
IVH & 0 & 0 & \\
Death & $4(3)$ & $3(3)$ & NS \\
\hline
\end{tabular}

Abbreviations: EC, early clipping group; LC, late clipping group; NS, not significant; PA, pulmonary artery; IVH, intraventricular hemorrhage; ( ), number of patients born in our hospital.
Overall, treatment of PDA in the lower body weight baby remains an ongoing debate among neonatologists for various issues such as the timing of pharmacological and surgical closure, the criteria for the treatment option, and the medication protocol for PDA closure. Based on our clinical results, we may need to change the strategy for surgical treatment of PDA in premature babies to avoid transporting sick patients to our facility. Further investigation is also warranted to determine which infants are most likely to benefit from surgical closure of PDA and which infants are best left untreated when pharmacological approaches are no longer available.

\section{Disclosure}

The authors report no conflict of interest in this work.

\section{References}

1. Raval MV, Laughon MM, Bose CL, Phillips JD. Patent ductus arteriosus ligation in premature infants: who really benefits, and at what cost? J Pediatr Surg. 2007;42(1):69-75; discussion 75.

2. Hsiao CC, Wung JT, Tsao LY, Chang WC. Early or late surgical ligation of medical refractory patent ductus arteriosus in premature infants. J Formos Med Assoc. 2009;108(1):72-77.

3. Johnston PG, Gillam-Krakauer M, Fuller MP, Reese J. Evidence-based use of indomethacin and ibuprofen in the neonatal intensive care unit. Clin Perinatol. 2012;39(1):111-136.

4. Fanos V, Marcialis MA, Bassareo PP, et al. Renal safety of non steroidal anti inflammatory drugs (NSAIDs) in the pharmacologic treatment of patent ductus arteriosus. J Matern Fetal Neonatal Med. 2011;24 Suppl 1:50-52.

5. Romagnoli C, Bersani I, Rubortone SA, Lacerenza S, De Carolis MP. Current evidence on the safety profile of NSAIDs for the treatment of PDA. J Matern Fetal Neonatal Med. 2011;24 Suppl 3:10-13.

6. Ohlsson A, Shah SS. Ibuprofen for the prevention of patent ductus arteriosus in preterm and/or low birth weight infants. Cochrane Database Syst Rev. 2011;7:CD004213.

7. Jones LJ, Craven PD, Attia J, Thakkinstian A, Wright I. Network meta-analysis of indomethacin versus ibuprofen versus placebo for PDA in preterm infants. Arch Dis Child Fetal Neonatal Ed. 2011;96(1): F45-F52.

8. Ohlsson A, Walia R, Shah SS. Ibuprofen for the treatment of patent ductus arteriosus in preterm and/or low birth weight infants. Cochrane Database Syst Rev. 2010;4:CD003481.

9. Gouyon JB, Kibleur Y. Efficacy and tolerability of enteral formulations of ibuprofen in the treatment of patent ductus arteriosus in preterm infants. Clin Ther. 2010;32(10):1740-1748.

10. Gork AS, Ehrenkranz RA, Bracken MB. Continuous infusion versus intermittent bolus doses of indomethacin for patent ductus arteriosus closure in symptomatic preterm infants. Cochrane Database Syst Rev. 2008;1:CD006071.

11. Porstmann W, Wiemy L, Warnke H, Gerstberger G, Romaniuk PA. Catheter closure of patent ductus arteriosus. 62 cases treated without thoracotomy. Radiol Clin North Am. 1971;9(2):203-218.

12. Rashkind WJ, Mullins CE, Hellenbrand WE, Tait MA. Nonsurgical closure of patent ductus arteriosus: clinical application of the Rashkind PDA Occluder System. Circulation. 1987;75(3):583-592.

13. Cambier PA, Kirby WC, Wortham DC, Moore JW. Percutaneous closure of the small (less than $2.5 \mathrm{~mm}$ ) patent ductus arteriosus using coil embolization. Am J Cardiol. 1992;69(8):815-816.

14. Ing FF, Bierman FZ. Percutaneous transcatheter coil occlusion of the patent ductus arteriosus aided by the nitinol snare: further observations. Cardiovasc Intervent Radiol. 1995;18(4):222-226. 
15. Ing FF, Mullins CE, Rose M, Shapir Y, Bierman FZ. Transcatheter closure of the patient ductus arteriosus in adults using the Gianturco coil. Clin Cardiol. 1996;19(11):875-879.

16. Tomita H, Fuse S, Chiba S. Catecholamine-induced ductus arteriosus constriction in children. Am J Cardiol. 1996;77(15):1372-1375.

17. Tomita H, Fuse S, Akagi T, et al. Coil occlusion for patent ductus arteriosus in Japan. Jpn Circ J. 1997;61(12):997-1003.

18. Grifka RG, Fenrich AL, Tapio JB. Transcatheter closure of patent ductus arteriosus and aorto-pulmonary vessels using non-ferromagnetic Inconel MReye embolization coils. Catheter Cardiovasc Interv. 2008;72(5): 691-695.

19. Glatz AC, Petit CJ, Gillespie MJ. Novel use of a modified Amplatzer Vascular Plug to occlude a patent ductus arteriosus in two patients. Catheter Cardiovasc Interv. 2008;72(1):82-86.

20. Pass R. Amplatzer duct occluder device: a new technology for the closure of the moderate-to-large-sized patent ductus arteriosus. Expert Rev Med Devices. 2006;3(3):291-296.

21. Masura J, Tittel P, Gavora P, Podnar T. Long-term outcome of transcatheter patent ductus arteriosus closure using Amplatzer duct occluders. Am Heart J. 2006;151(3):755.e7-755.e10.

22. Lin CC, Hsieh KS, Huang TC, Weng KP. Closure of large patent ductus arteriosus in infants. Am J Cardiol. 2009;103(6):857-861.

23. Krichenko A, Benson LN, Burrows P, Moes CA, McLaughlin P, Freedom RM. Angiographic classification of the isolated, persistently patent ductus arteriosus and implications for percutaneous catheter occlusion. Am J Cardiol. 1989;63(12):877-880.

24. Ing FF, Sommer RJ. The snare-assisted technique for transcatheter coil occlusion of moderate to large patent ductus arteriosus: immediate and intermediate results. J Am Coll Cardiol. 1999;33(6): $1710-1718$.

25. Ing FF, Recto MR, Saidi A, Denfield S, Mullins CE. A method providing bidirectional control of coil delivery in occlusions of patent ductus arteriosus with shallow ampulla and Pott's shunts. Am J Cardiol. 1997, 79(11):1561-1563.

26. Prieto LR, Latson LA, Dalvi B, Arbetman MM, Ebeid MR, Lamorgese TT. Transcatheter coil embolization of abnormal vascular connections using a new type of delivery catheter for enhanced control. Am J Cardiol. 1999;83(6):981-983, A10.

27. Gorenflo M, Ulmer HE, Brockmeier K. Successful closure of the arterial duct in the setting of rubella syndrome. Cardiol Young. 2002;12(2): 200-202.

28. Ussia GP, Mule M, Caruso E, Aiello R, Tamburino C. Combined endothelin receptor antagonist and transcatheter interventional therapy of patent ductus arteriosus with severe pulmonary artery hypertension. Int J Cardiol. 2007;116(3):427-429.

29. Clyman RI. Surgical ligation of the patent ductus arteriosus: treatment or morbidity? J Pediatr. 2012;161(4):583-584.

30. Benjamin JR, Smith PB, Cotton CM, Jaggers J, Goldstein RF, Malcolm WF. Long-term morbidities associated with vocal cord paralysis after surgical closure of a patent ductus arteriosus in extremely low birth weight infants. $J$ Perinatol. 2010;30(6):408-413.
31. Bedard MP, Shankaran S. Closure of PDA re risk of IVH. J Pediatr. 1983;102(6):1015-1016

32. Clyman RI, Couto J, Murphy GM. Patent ductus arteriosus: are current neonatal treatment options better or worse than no treatment at all? Semin Perinatol. 2012;36(2):123-129.

33. Mirea L, Sankaran K, Seshia M, et al. Treatment of patent ductus arteriosus and neonatal mortality/morbidities: adjustment for treatment selection bias. J Pediatr. 2012;161(4):689-694. e1.

34. Madan JC, Kendrick D, Hagadom JI, Frantz ID 3rd; National Institute of Child Health and Human Development Neonatal Research Network. Patent ductus arteriosus therapy: impact on neonatal and 18-month outcome. Pediatrics. 2009;123(2):674-681.

35. Kabra NS, Schmidt B, Roberts RS, Doyle LW, Papile L, Fanaroff A. Neurosensory impairment after surgical closure of patent ductus arteriosus in extremely low birth weight infants: results from the Trial of Indomethacin Prophylaxis in Preterms. J Pediatr. 2007;150(3): 229-234, 234.e1.

36. Vida VL, Lago P, Salvatori S, et al. Is there an optimal timing for surgical ligation of patent ductus arteriosus in preterm infants? Ann Thorac Surg. 2009;87(5):1509-1515; discussion 1515-1516.

37. Malviya M, Ohlsson A, Shah S. Surgical versus medical treatment with cyclooxygenase inhibitors for symptomatic patent ductus arteriosus in preterm infants. Cochrane Database Syst Rev. 2008;1:CD003951.

38. Lemmers PM, Toet MC, van Bel F. Impact of patent ductus arteriosus and subsequent therapy with indomethacin on cerebral oxygenation in preterm infants. Pediatrics. 2008;121(1):142-147.

39. Vanderhaegen J, De Smet D, Meyns B, Van De Velde M, Van Huffel S, Naulaers G. Surgical closure of the patent ductus arteriosus and its effect on the cerebral tissue oxygenation. Acta Paediatr. 2008;97(12): $1640-1644$.

40. Jhaveri N, Moon-Grady A, Clyman RI. Early surgical ligation versus a conservative approach for management of patent ductus arteriosus that fails to close after indomethacin treatment. J Pediatr. 2010; 157(3):381-387, 387.e1.

41. Wickremasinghe AC, Rogers EE, Piecuch RE, et al. Neurodevelopmental outcomes following two different treatment approaches (early ligation and selective ligation) for patent ductus arteriosus. J Pediatr. 2012;161(6): 1065-1072.

42. Teixeira LS, Shivananda SP, Stephens D, Van Arsdell G, McNamara PJ. Postoperative cardiorespiratory instability following ligation of the preterm ductus arteriosus is related to early need for intervention. $J$ Perinatol. 2008;28(12):803-810.

43. Smith ME, King JD, Elsherif A, Muntz HR, Park AH, Pouretas PC. Should all newborns who undergo patent ductus arteriosus ligation be examined for vocal fold mobility? Laryngoscope. 2009;119(8):1606-1609.

44. Clyman R, Cassady G, Kirklin JK, Collins M, Philips JB 3rd. The role of patent ductus arteriosus ligation in bronchopulmonary dysplasia: reexamining a randomized controlled trial. J Pediatr. 2009;154(6):873-876.
Pediatric Health, Medicine and Therapeutics

\section{Publish your work in this journal}

Pediatric Health, Medicine and Therapeutics is an international, peerreviewed, open access journal publishing original research, reports, editorials, reviews and commentaries. All aspects of health maintenance preventative measures and disease treatment interventions are addressed within the journal. Practitioners from all disciplines are invited to submit

\section{Dovepress}

their work as well as healthcare researchers and patient support groups The manuscript management system is completely online and includes a very quick and fair peer-review system. Visit http://www.dovepress.com/ testimonials.php to read real quotes from published authors. 